\title{
IDENTIFICATION OF THE HAIR OF TASMANIAN MAMMALS
}

\author{
by Robert J. Taylor
}

(with 5 text-figures and 10 plates)

\begin{abstract}
TAYLOR, R.J., 1985 (31:vii): Identification of the hair of Tasmanian mammals. Pap.Proc.R.Soc.Tasm. 119:69-82. https://doi.org/10.26749/rstpp.119.69 ISSN 0080-4703. Department of Zoology, University of Tasmania, Hobart, Tasmania, Australia.

Photographs of the hair structure of the five species of I asmanian mammals (Sarcopnilus narrisu. Thylacinus cynocephalus, Bettongia gaimardi, Cercartetus lepidus and Pseudomys higginsi) which have not been described by Brunner \& Coman (1974) are presented. A key to the hair of forty Tasmanian mammals is provided to allow the identification of unknown samples. The key can be used in mammal surveys and in carnivore dietary studies. Key Words:- marsupial hair, eutherian hair, Tasmania.
\end{abstract}

\section{INTRODUCTION}

Lyne \& McMahon (1951) carried out a preliminary investigation of the structure of the hair of Tasmanian marsupials. Their aim was to investigate the taxonomic significance of hair structure but they were unable to achieve their objective of constructing a key to enable the identification of the hair of different species. They also did not present any data for the eutherian mammals in Tasmania. Brunner \& Coman (1974) refined the techniques of hair identification and provided photographs of hair structure which could be used to identify the hair of mammals occurring in Victoria. Similar photographs have also been provided for mammals occurring in the south of Western Australia (Valente \& Woolley 1982). The ability to identify hair samples has proved to be an invaluable tool in dietary studies of carnivores (Brunner, Lloyd \& Coman, 1975, Jones \& Coman 1981) and in mammal surveys, where hair traces found in hair sampling tubes (Suckling 1978 ) or in predator scats (Brunner, Amor \& Stevens 1976) may be the only method of detecting the presence of a species.

In this paper data are presented on the hair structure of five species of mammals occurring in Tasmania which have not been described by Brunner \& Coman (1974). A key is also provided to allow the hair of forty Tasmanian mammals to be identified. This study was undertaken because of the need to identify hair samples obtained during survey work and carnivore dietary studies conducted by members of the Zoology Department at the University of Tasmania.

\section{HAIR IDENTIFICATION}

Cross-sections, whole mounts and scale casts were prepared using the techniques outlined in Brunner \& Coman (1974). Only terrestrial mammals were included in the study (i.e. bats and seals excluded). Photographs of the hair structure of the five native species present in Tasmanian which are not illustrated in Brunner \& Coman (1974) (i.e. Sarcophilus harrisii, Thylacinus cynocephalus, Bettongia gaimardi, Cercartetus lepidus and Pseudomys higginsi) a re given in Plates 1-10. The magnification for cross sections is approximately 425 , and for whole mounts and scale patterns is 270. Terminology used to describe hair structure follows Brunner \& Coman (1974).

Brunner \& Coman (1974) and Valente \& Wooley (1982) both arranged species into groups with similar structure and relied on a visual comparison between unknown samples and the photographs provided to key out hair. Brunner \& Coman (1974) also provided a diagnostic feature for each species, wherever possible. In this paper the key has been made more dichotomous than in the other two studies (op. cit.).

\section{KEY TO THE HAIR OF TASMANIAN MAMMALS}

Initial separation of groups is based on the cross-sectional appearance of primary guard hairs.

A. Predominantly circular in

cross-section .................. GROUP I

B. Predominantly oval in

cross-section ................ GROUP 2

C. Predominantly oblong in

cross-section

GROUP 3 
D. Predominantly eye or lemon-shaped in cross-section .................. GROUP 4

E. Predominantly reniform or concavo-convex in cross-section .............. GROUP 5

F. Predominantly dumb-bell-shaped in cross-section ................ GROUP 6

G. Predominantly flattened or cigar-shaped in cross-section ................. GROUP 7

\section{Group 1}

1. Maximum diameter of hair less than $40 \mu \mathrm{m}$.................. Cercartetus nanus and $C$. lepidus

Maximum diameter of hair greater than

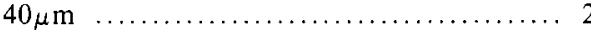

2. All hairs either black or white ................... Sarcophilus harrisii Other colours preent ................ 3

3. Orange-brown pigment granules present around the medulla of many of the guard hairs (unless only belly fur or hairs from the white spots present in sample) ..... Dasyurus maculatus Only dark pigment granules present around medulla of many of the guard hairs (unless only belly fur or hairs from the white spots present in sample) ............. Dasyurus viverrinus

\section{Group 2}

1. Medulla much reduced or absent ......... 2 Medulla prominent $\ldots \ldots \ldots \ldots \ldots \ldots \ldots \ldots, 3$

2. Very wavy hair; ma ximum diameter of hairs less than $60 \mu \mathrm{m}$..................... Ovis aries Bristle hairs; maximum diameter of hairs up to $220 \mu \mathrm{m} \ldots \ldots \ldots \ldots \ldots \ldots \ldots \ldots$. Sus scrofa

3. Very large medulla ............ Dama dama Medulla not large .................. 4

4. Maximum diameter of hairs less than

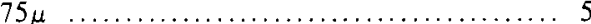
Maximum diameter of hairs greater than $75 \mu \mathrm{m} \ldots \ldots \ldots \ldots \ldots \ldots \ldots \ldots \ldots .6 . \ldots \ldots$

5. Maximum diameter of hairs up to $40 \mu \mathrm{m}$; cortex narrower than in Antechinus (see Brunner \& Coman 1974, pages $62,64,68)$..... Sminthopsis leucopus Maximum diameter of hairs up to $70 \mu \mathrm{m}$; cortex wider than in Sminthopsis

...... Antechinus swainsonii and A. minimus

6. Underhairs have narrow cortex ... Felis calus Cortex of underhairs is medium or large ... 7

7. Spindle-shaped aggregations of pigment gran ules present in cortex (see Brunner \& Coman 1974, page 97) ................ Bos taurus No spindle-shaped aggregations of pigment granules present in cortex $\ldots \ldots \ldots \ldots \ldots \ldots 8$
8. Medulla of guard hairs is widest in proximal one-third ................ Equus caballus Medulla of guard hairs is widest in distal half Canis familiaris

\section{Group 3}

1. Medulla reduced or absent $\ldots \ldots \ldots \ldots \ldots \ldots 2$ Medulla prominent $\ldots \ldots \ldots \ldots \ldots \ldots \ldots \ldots, 3$

2. Hairs usualy less than $3 \mathrm{~cm}$ in length; no medulla; maximum diameter of hairs up to $350 \mu \mathrm{m}$............ Tachyglossus aculeatus Many hairs greater than $3 \mathrm{~cm}$ in length; small medulla present in some hairs in cross section; maximum diameter of hair up to $250 \mu \ldots \ldots \ldots \ldots \ldots \ldots$ Vombatus ursinus

3. Medulla with characteristic lattice pattern (see Brunner \& Coman 1974, page 127); length to breadth ratio of shield region of guard hair in cross-section usually 2.5 or greater

................... Hydromys chrysogaster Medulla lattice, if present, unlike that in Hydromys; length to breadth ratio of crosssection of hairs less than $2.5 \ldots \ldots \ldots \ldots \ldots 4$

4. Scale pattern on primary guard hair is near or close irregular wave; hairs generally less than $25 \mathrm{~mm}$ long; hair is brown at base, pale sandy colour on upper half with a brown tip or all of hair a pale sandy colour

.................. Thylacinus cynocephalus If wave scale pattern is present then it is regular (not irregular); guard hairs usually greater than $25 \mathrm{~mm}$ in length (except in some Bettongia); base of hair grey, or if brown then hairs longer than $25 \mathrm{~mm} \ldots \ldots \ldots \ldots \ldots \ldots \ldots \ldots \ldots$

5. Many hairs with obvious white bands; diameter of primary guard hairs generally less than $75 \mu \mathrm{m}$............... Macropus giganteus Hairs without obvious white bands; maximum diameter of primary guard hairs greater than 75 $\mu \mathrm{m} \ldots \ldots \ldots \ldots \ldots \ldots \ldots \ldots \ldots \ldots \ldots \ldots \ldots \ldots \ldots \ldots$

6. Base of hair grey brown, changing to brown with white band and brown or black tip (or hair all white) ........... Macropus rufogriseus Base of hair light grey..$\ldots \ldots \ldots \ldots \ldots \ldots$. 7

7. Underhairs oval in cross section .................... Thylogale billardierii Underhairs circular in cross section ...... 8

8. Larger guard hairs and overhairs have a more oval or slightly reniform appearance in cross section in comparison with Potorous

Bettongia gaimardi Larger guard hairs and overhairs have a moe oblong appearance in comparison with Bettongia ................... Potorous tridactylus 


\section{Group 4}

1. Diameter of hairs usually $20 \mu \mathrm{m}$ or less; maximum width $30 \mu \mathrm{m}$....... Petaurus breviceps Many hairs greater than $30 \mu \mathrm{m}$ wide

2. Maximum diameter of hairs $50 \mu \mathrm{m}$; hairs are circula $r$ in cross section near base

Pseudocheirus peregrinus Maximum diameter of hairs $70 \mu \mathrm{m}$; hairs are eye-shaped or oval in cross section near base ................. Trichosurus vulpecula

\section{Group 5}

1. Hairs with divided medulla $\ldots . . . \ldots \ldots \ldots, 2$ Hairs with bilobed or large medulla ........ 3

2. Maximum diameter of hair up to $180 \mu \mathrm{m}$ appearance of concave depression in crosssection is shallower than in Isoodon (see Brunner \& Coman 1974, pages 140 and 144)

Perameles gunnil

Diameter of many hairs greater than $200 \mu \mathrm{m}$; concave depression on hairs much more prominent than in Perameles .... Isoodon obesulus

3. Primary guard hair at widest point tending to be more reinform than concavo-convex in cross section ............................ 4 Primary guard hair at widest point tending to be more concavo-convex than reinform in crosssection

4. Maximum diameter of hairs up to $40 \mu \mathrm{m}$.......... Pseudomys novaehollandiae Maximum diameter of hairs greater than $40 \mu \mathrm{m}$................ Pseudomys higginsi Mastacomys fuscus

5. Maximum diameter of hairs up to $50 \mu \mathrm{m}$..................... Mus musculus Maximum diameter of hairs greater than

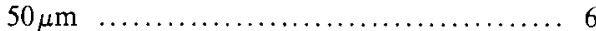

6. Proximal half of primary guard hair is usually dark grey and is noticably thinner than in the introduced rats (see Brunner \& Coman 1974 , pages 146,148 and 152) .... Rattus lutreolus Proximal half of primary guard hair is usually white or sometimes very light grey ........ 7

7. Cross section of primary guard hairs is almost cigar-shaped ............. Rattus norvegicus Cross section of primary guard hair not tending to cigar-shape ................ Rattus rattus

\section{Group 6}

1. Scalloped medulla pattern (see Brunner \& Coman 1974, page 167); diameter of many hairs greater than $150 \mu \mathrm{m}$
Multiserial medulla pattern; maximum diameter of hairs up to $150 \mu \mathrm{m}$................... 2

2. Scale pattern in shield region of primary guard hair is more irregular than in Oryctolagus (see Brunner \& Coman 1974, pages 169 and 171)

Lepus europaeus Scale pattern in shield region of primary guard hair is regular ........ Oryctolagus cuniculus

\section{Group 7}

1.

Ornithorhynchus anatinus

\section{DISCUSSION}

The first step in identifying an unknown hair sample is to classify the appearance of the primary guard hairs in cross section. The hair to be identified should thus be positioned so as to include a cross section of the primary guard hair at its widest point. In some predator scats, because the hair has been well masticated, it is not possible to select a tuft of hair. In this case several sections should be made so as to obtain a representative sa mple of cross-sectional shapes. Only photographs of the hair of Tasmanian mammals that are not illustrated in Brunner \& Coman (1974) are given in this paper. Thus the present paper needs to be used in conjunction with Brunner \& Coman (1974) in order to identify a sample of hair. It shold be noted that the key is based on the structure of hairs found on the main pelage. Hair from the extremities can sometimes differ from that on the main pelage and hence it is important to have a set of skins available for reference.

I have classified the hairs of Vombatus ursinus, Macropus giganteus, $M$. rufogriseus, Thylogale billardierii, Bettongia gaimardi and Potorous tridactylus as having a predominantly oblong ap pearance in cross-section rather than an oval appearance as did Brunner \& Coman (1975). The interpretation of the difference between these two groups is rather subjective; however, Valente $\&$ Woolley (1982) also classified the hair of the Macropodoidea as having an oblong appearance. Pseudomys novaehollandiae was placed in the oblong group by Brunner \& Coman (1974) whereas I have placed it in the group with a concavo-convex appearance. The hair of $P$. novaehollandiae in cross-section has a very similar appearance to that of Mastacomys fuscus which Brunner \& Coman (1974) placed in the concavo-convex group. The hair of the other member of the genus Pseudomys in Tasmania ( $P$. higginsi) also has hair with a concavo-convex appearance in cross-section.

It has not been possible to differentiate the hair of all the species of mammals occurring in 


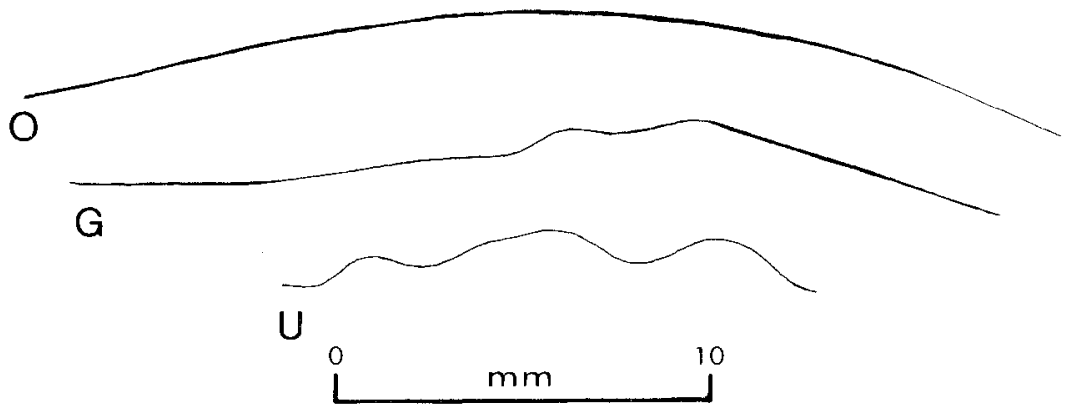

FIG. 1 - Pseudomys higginsi Hair profiles: 0 = over hair; $\mathrm{G}=$ guard hair; $\mathbf{U}=$ under hair.

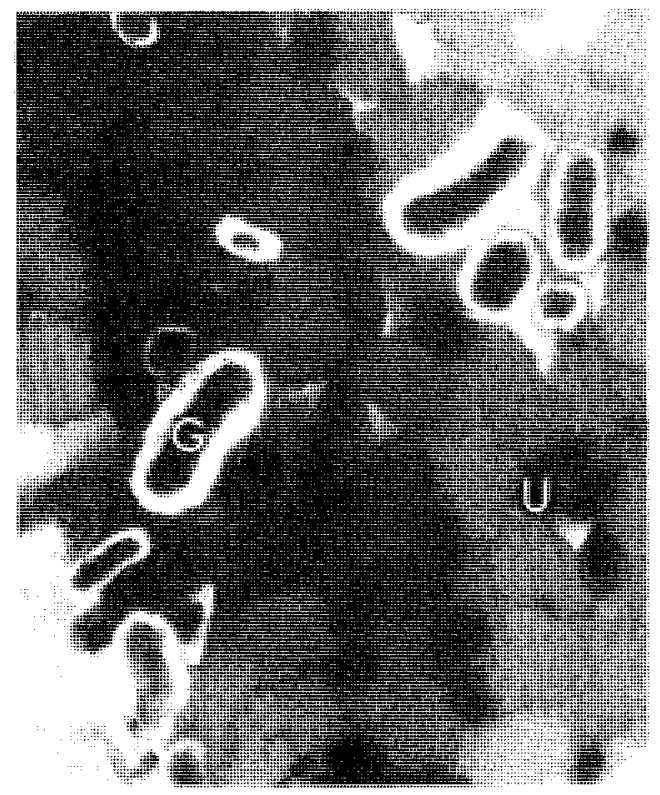

A

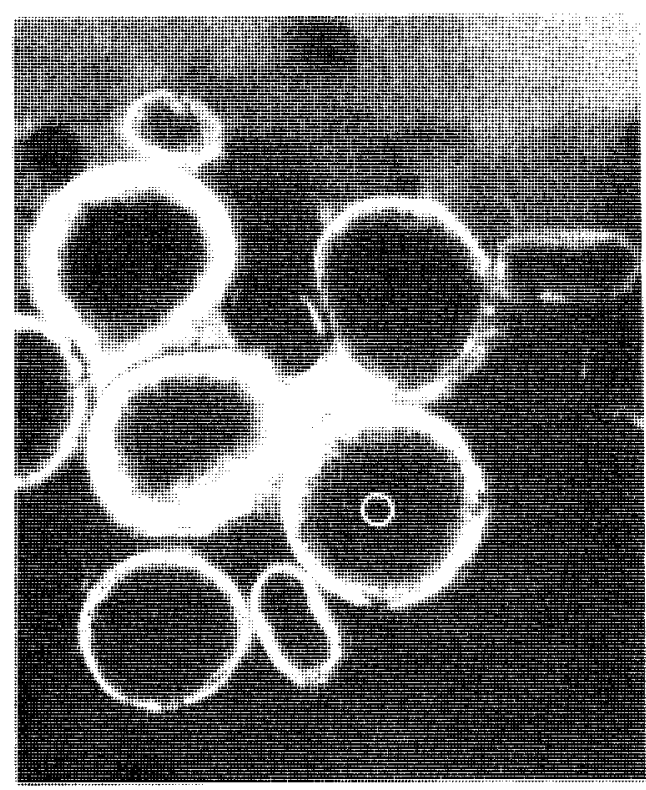

B

PLATE 1

PLATE 1 - Figures A, B: cross-sections of hairs of Pseudomys higginsi.

PLATE 2 (facing) - Figures A to D: whole mounts of hairs of Pseudomys higginsi. A, under hair in proximal (left) and distal (right) regions; B, small guard hair in distal region; C, primary guard hair in proximal region; $\mathrm{D}$, primary guard hair in shield region.

Figures E to I: scale patterns of hairs of Pseudomys higginsi. E, under hair in proximal region; F, under hair in distal region; $\mathrm{G}$, primary guard hair in proximal region; $\mathrm{H}$, primary guard hair in mid-shaft region; $\mathrm{I}$, primary guard hair in distal region. 


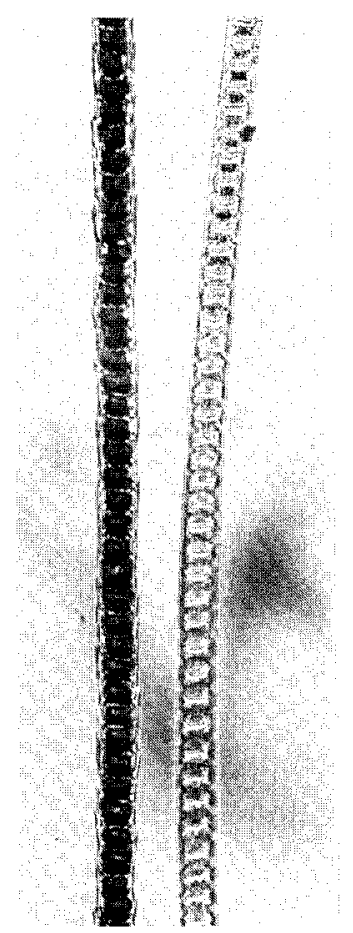

A

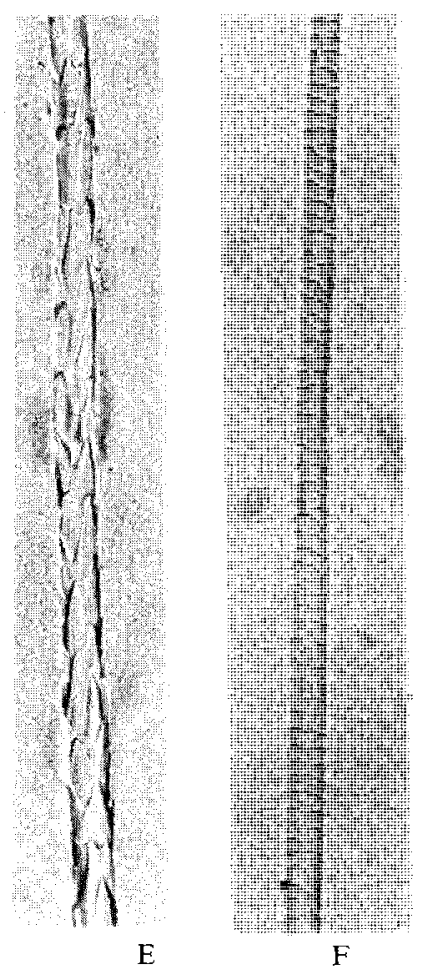

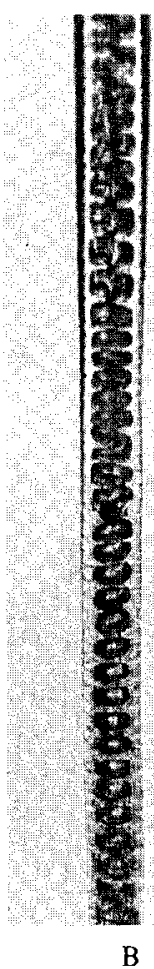

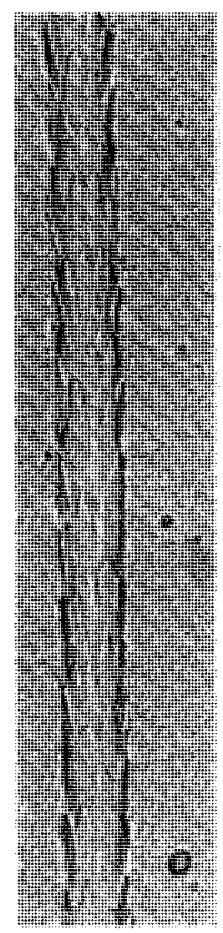

G
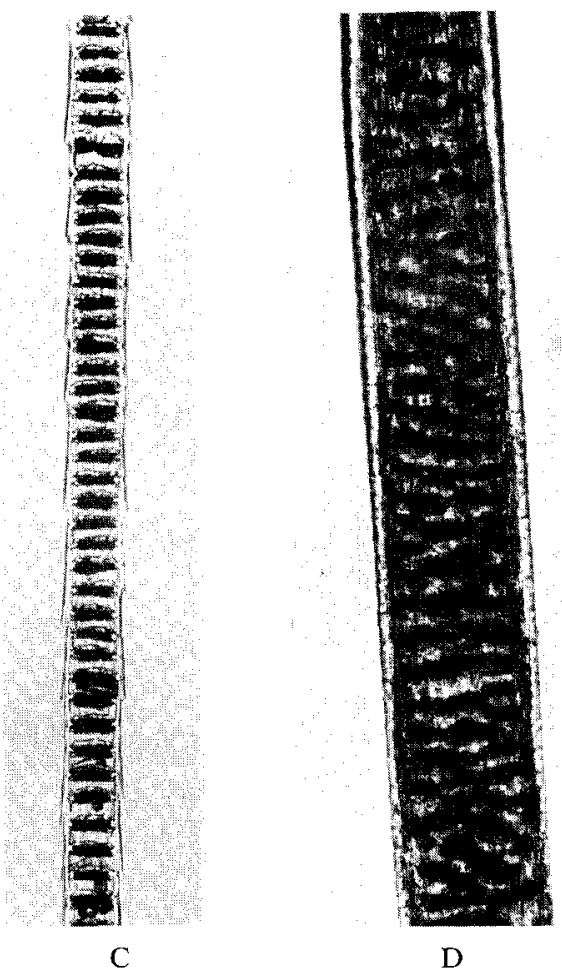

D
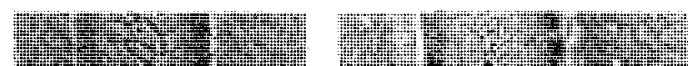

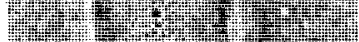
III) 14tHI

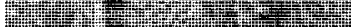
1 II 1) 14) 1. (1) 1) (1) (I) DOt 1) III (1) 1)

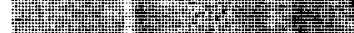

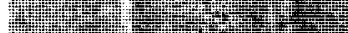

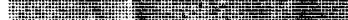
W 15 1014 (1) 14 (3) Hit 14t) 1) (t) I

PLATE 2 


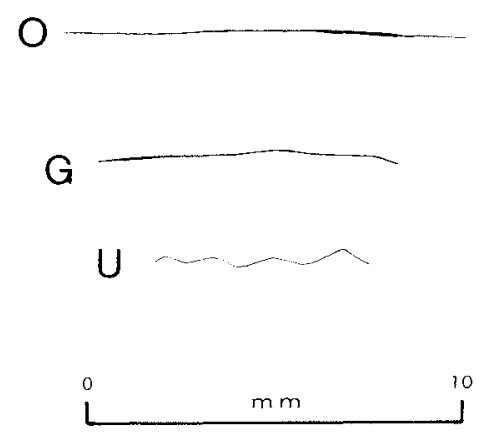

FIG. 2 - Cercartetus lepidus Hair profiles: $0=$ over hair; $\mathrm{G}=$ guard hair; $\mathrm{U}=$ under hair.

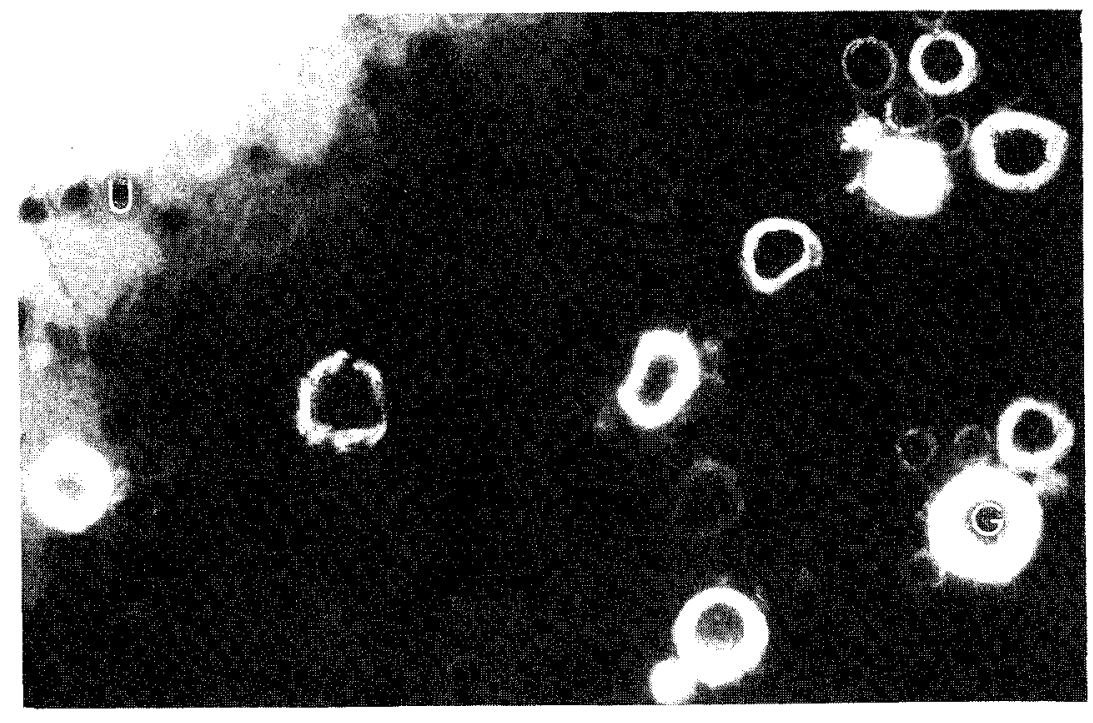

PLATE 3

PLATE 3 - Cross-sections of hairs of Cercartetus lepidus.

PLATE 4 (facing) - Figures A to E: whole mounts of hairs of Cercartetus lepidus. A, guard hair in proximal region; B, guard hair in mid region; $\mathrm{C}$, guard hair in distal region; D, primary guard hair in proximal region; $\mathrm{E}$, primary guard hair in shield region.

Figures $\mathrm{F}$ to $\mathrm{H}$ : scale patterns of primary guard hairs of Cercartetus lepidus. F, proximal; G, transition between shaft and shield region; $\mathrm{H}$, distal. 


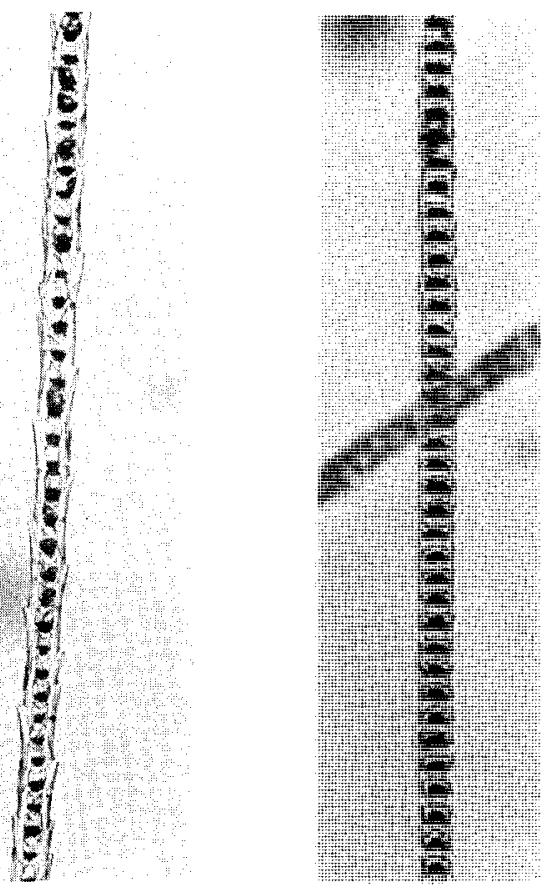

A

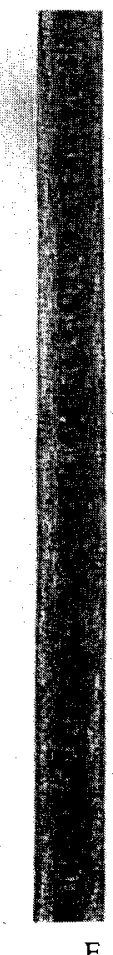

B

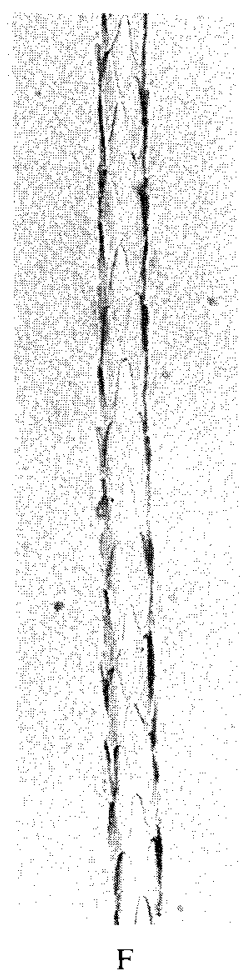

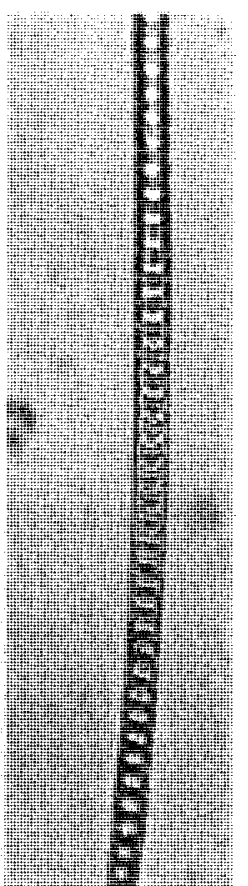

C

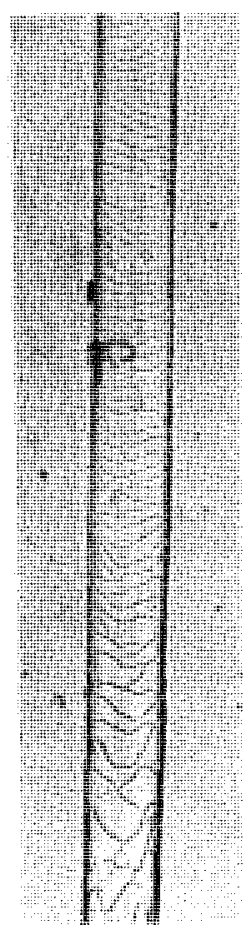

G

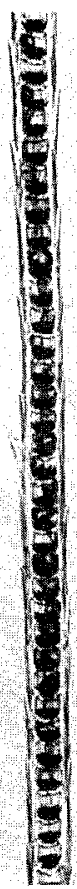

D

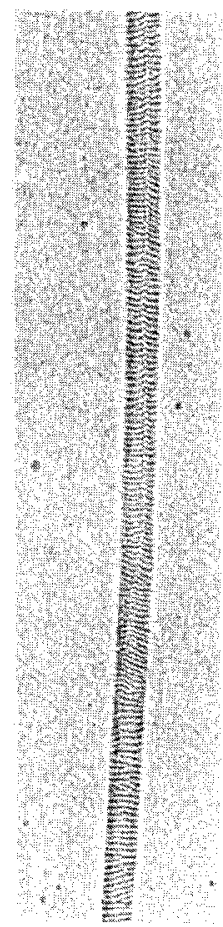

$\mathrm{H}$

PLATE 4 


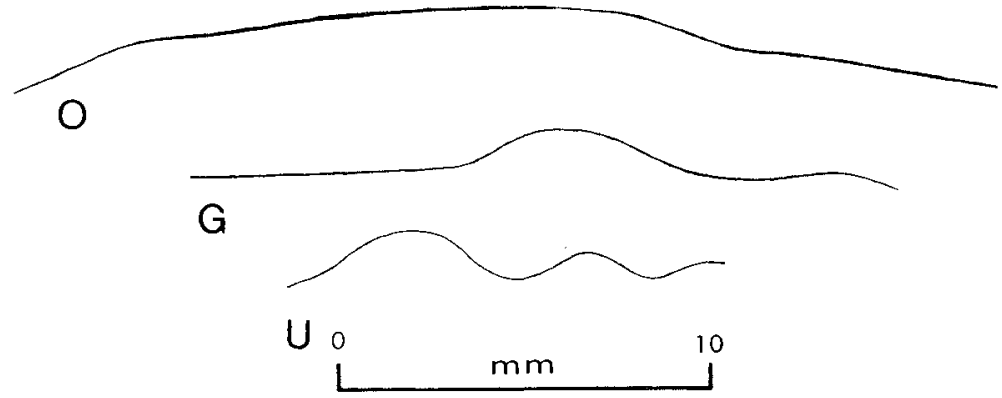

FIG. 3 - Thylacinus cynocephalus. Hair profiles: $0=$ over hair; $\mathrm{G}=$ guard hair; $\mathrm{U}=$ under hair.

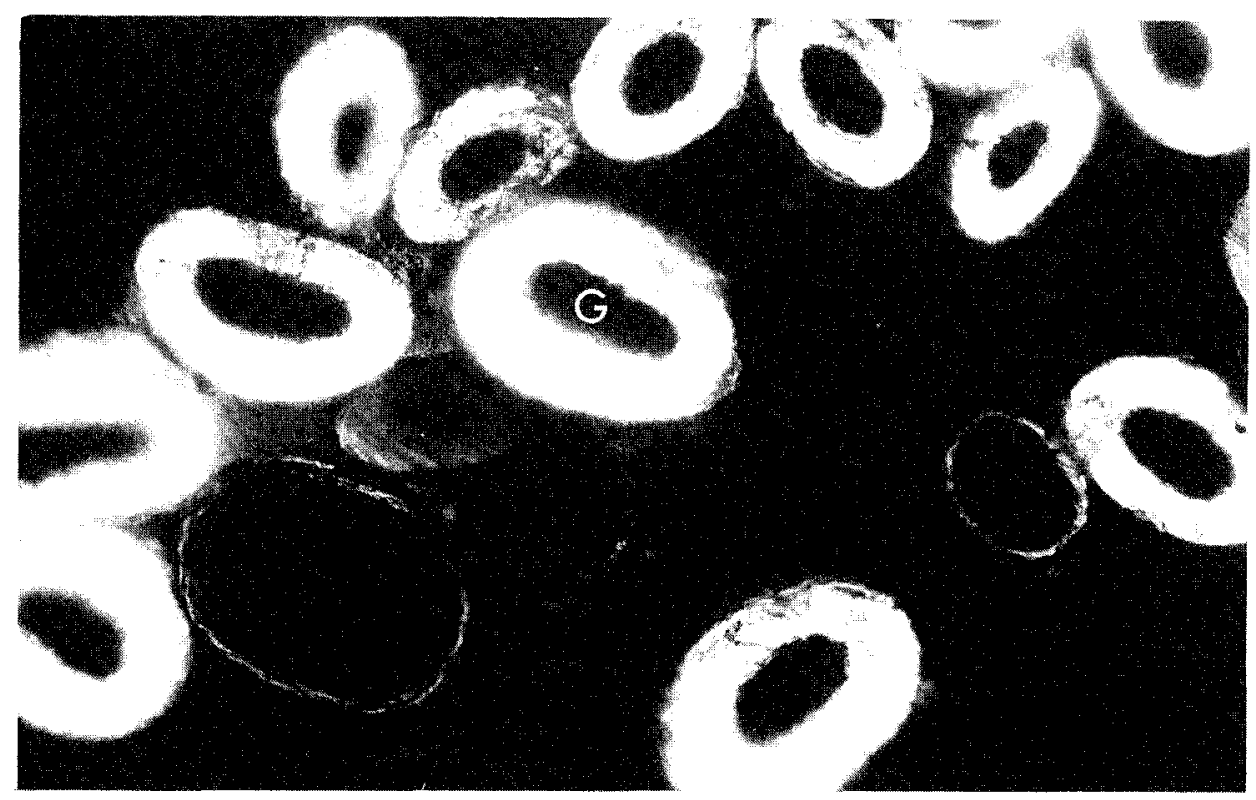

PLATE 5

PLATE 5 - Cross-sections of hairs of Thylacinus cynocephalus.

PLATE 6 (facing) - Figures A to D: whole mounts of hairs of Thylacinus cynocephalus. A, under hair in proximal region; B, under hair in distal region; C, primary hair in proximal region; D, primary guard hair in shield region.

Figures $\mathrm{E}$ to $\mathrm{H}$ : scale patterns of hairs of Thylacinus cynocephalus. E, under hair in proximal region; F, under hair in distal region; $\mathrm{G}$, primary guard hair in proximal region; $\mathrm{H}$, primary guard hair in mid-shaft region. 


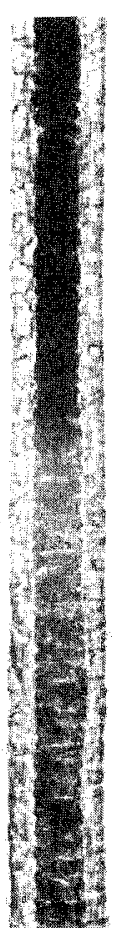

A

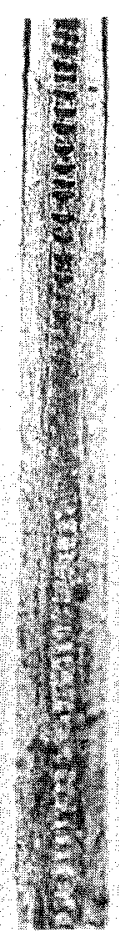

B

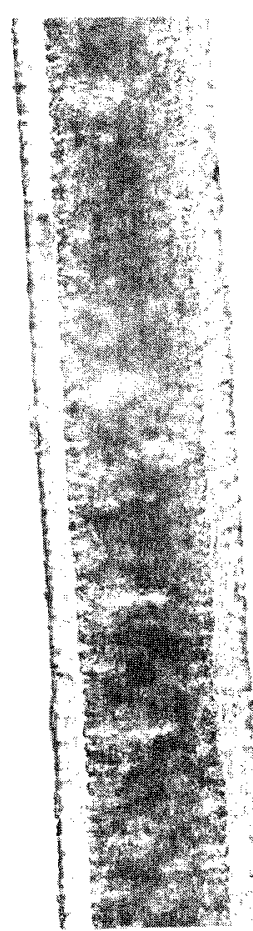

C

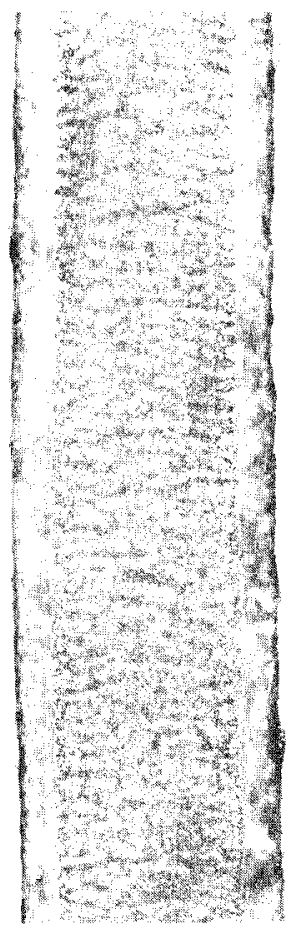

D
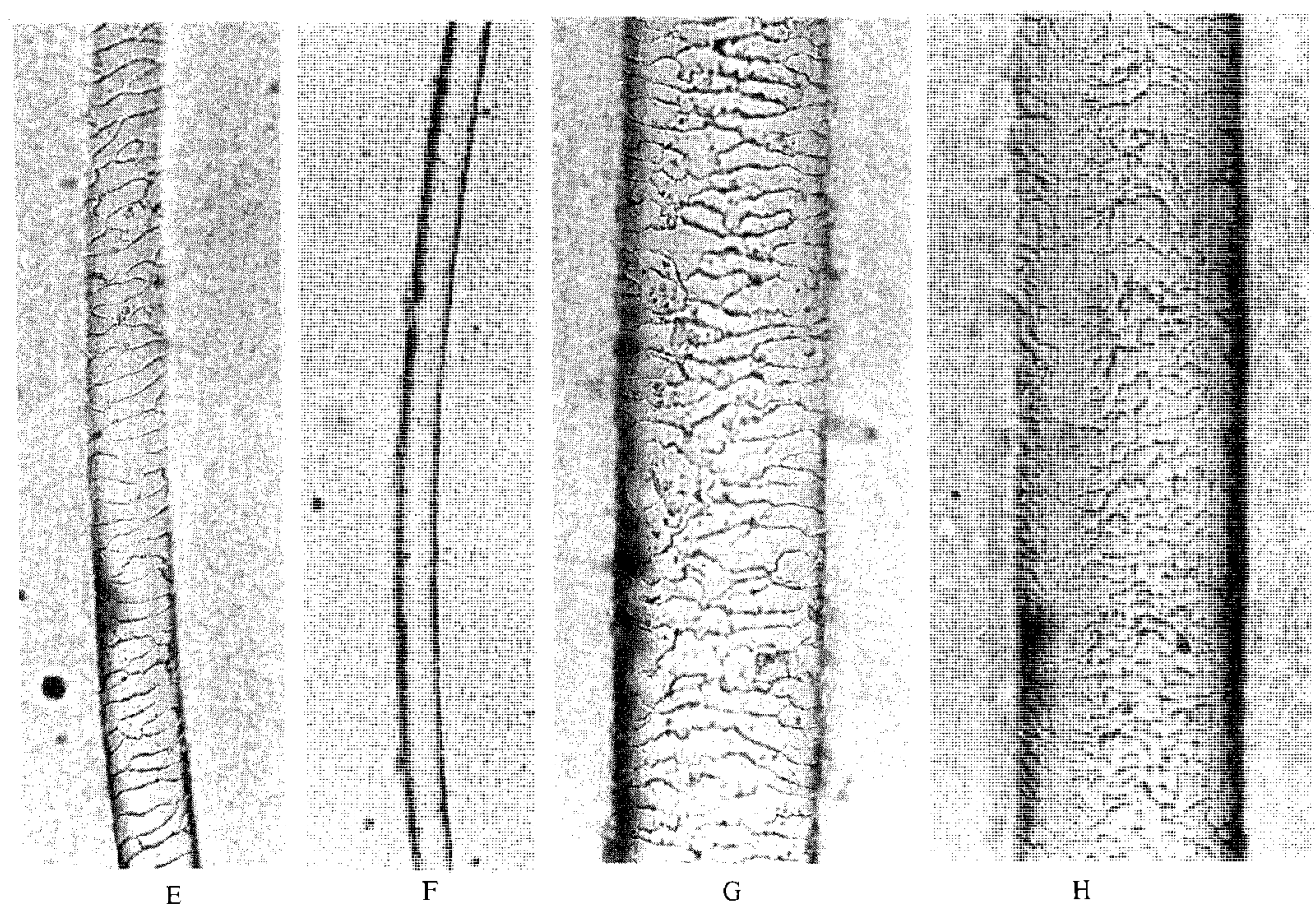

$\mathrm{H}$

PLATE 6 


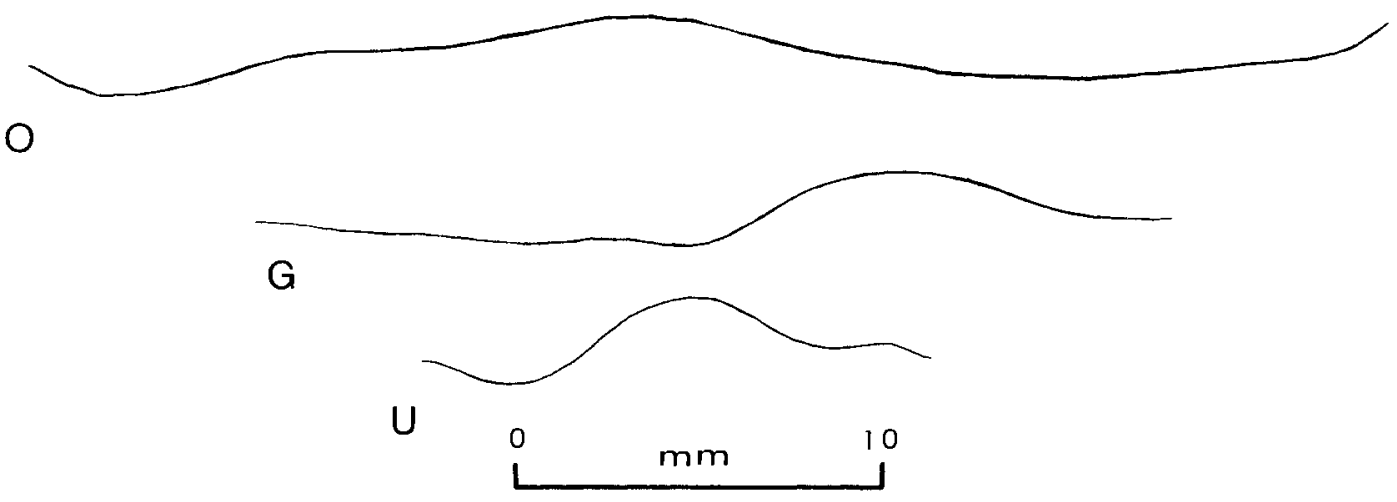

FIG. 4 - Sarcophilus harrisii. Hair profiles: 0 = over hair; $\mathrm{G}=$ guard hair; $\mathrm{U}=$ under hair.

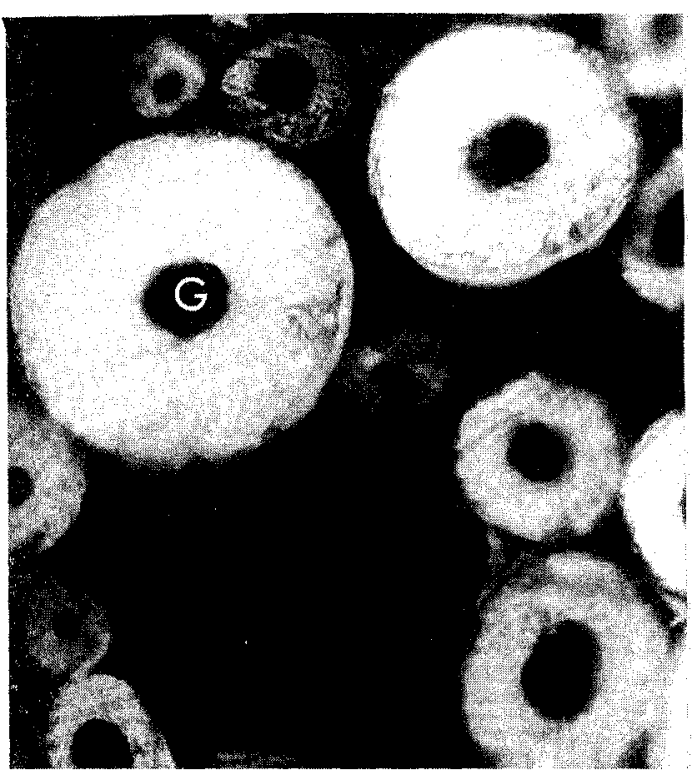

A

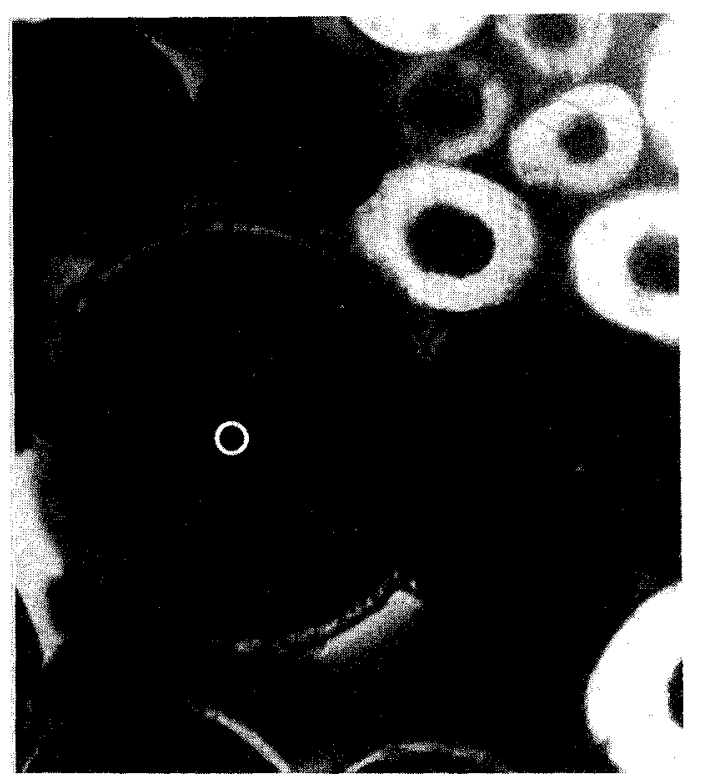

B

PLATE 7

PLATE 7 - Figures A, B: Cross-sections of hairs of Sarcophilus harrisii.

PLATE 8 (facing) - Figures A to F: whole mounts of hairs of Sarcophilus harrisii. A, under hair in proximal region; $\mathrm{B}$, under hair in distal region; C, guard hair in proximal region; D, guard hair in mid-shaft region;E, guard hair in distal region; F, primary guard hair (white) in distal region.

Figures G to I: scale patterns of hairs of Sarcophilus harrisii. G, under hair in proximal region; H, under hair in distal region; I, predominant pattern along the length of the primary guard hair. 
Identification of the hair of Tasmanian mammals.
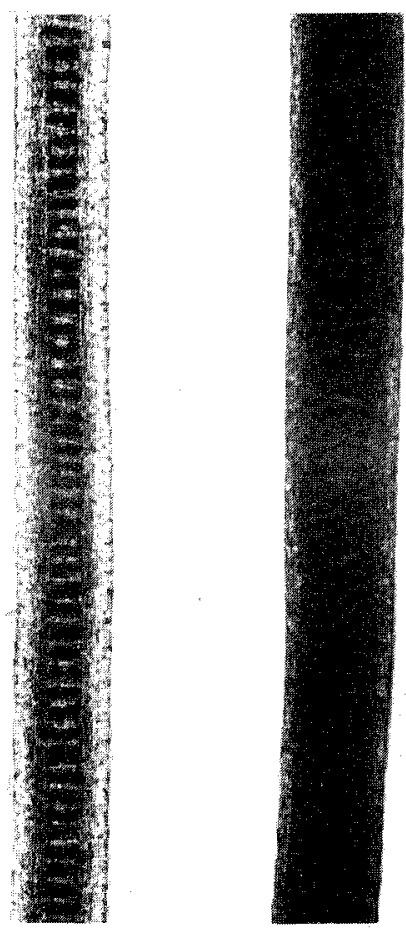

A

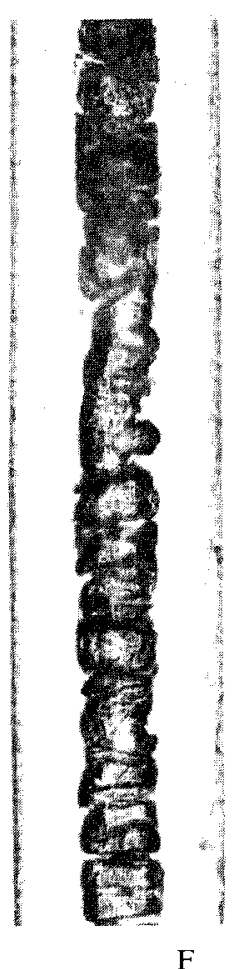

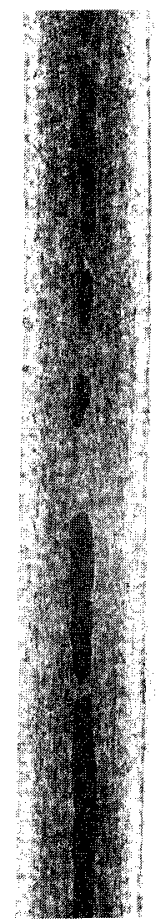

$\mathrm{C}$

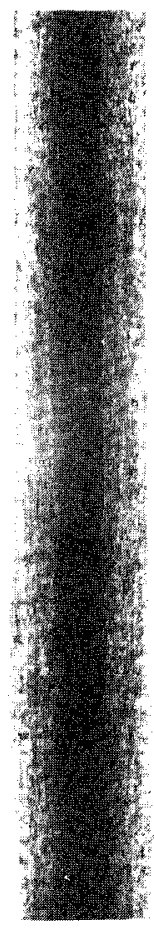

D

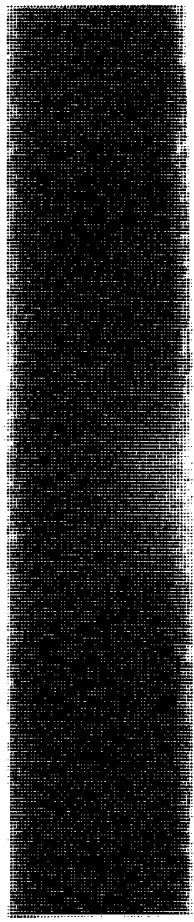

E

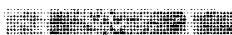
t. 1) (1)

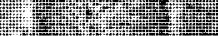

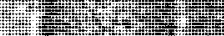

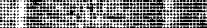
tytetetety (1)

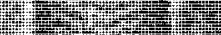

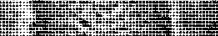

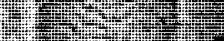
(1) Hatextety (1)

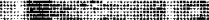

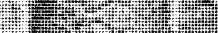
(y) 1.texty 1)

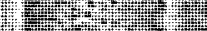

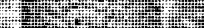
1) theteytat: tetwet 14ten:

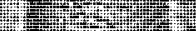

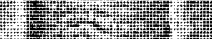
titenty

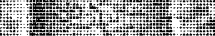
(1)

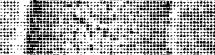
I

PLATE 8 


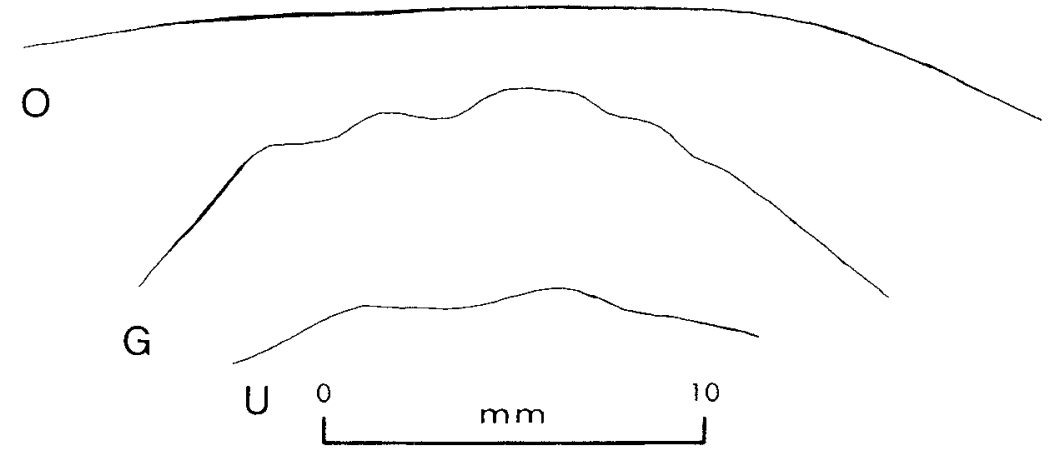

FIG. 5 - Bettongia gaimardi. Hair profiles: $0=$ over hair; $G=$ guard hair; $U=$ under hair.

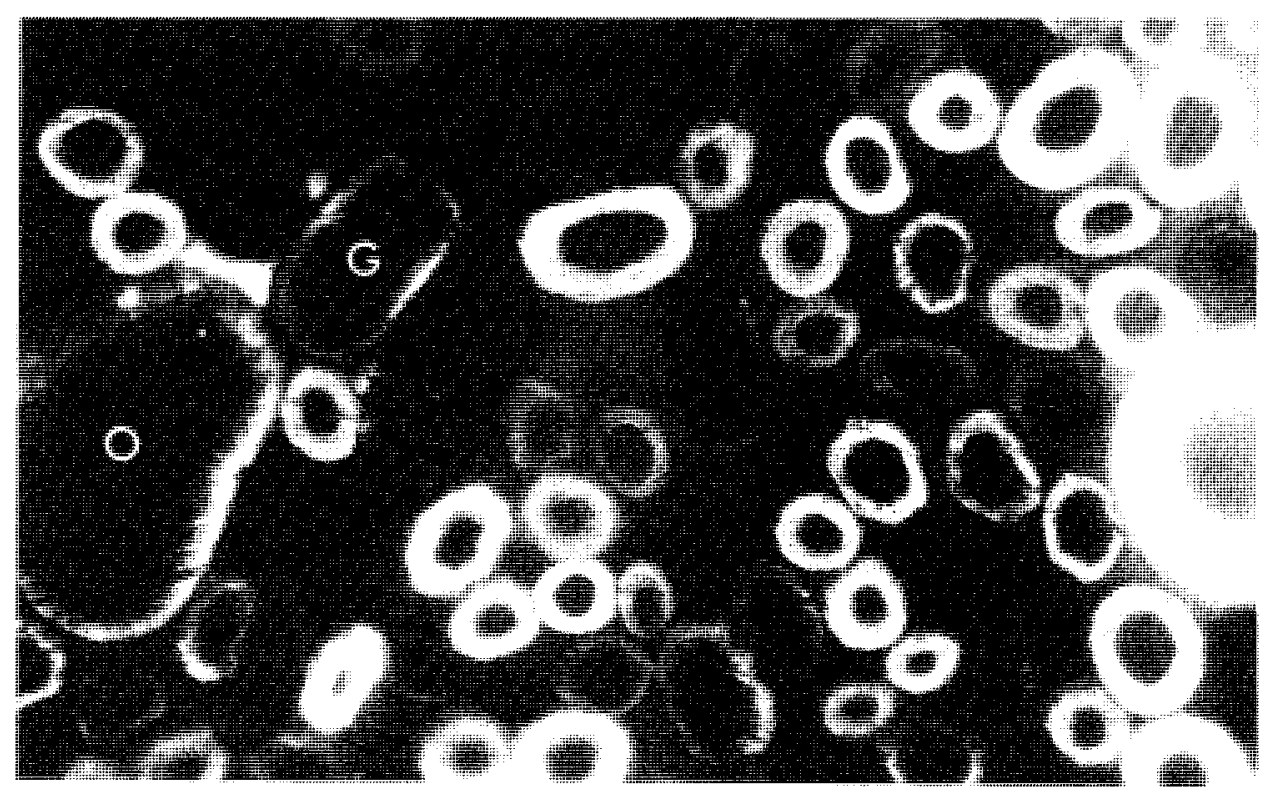

PLATE 9

PLATE 9 - Cross-sections of hairs of Bettongia gaimardi.

PLATE 10 (facing) - Figures A to D: whole mounts of hairs of Bettongia gaimardi. A, under hair in proximal region; B, under hair in distal region; C, guard hair in proximal (left) and distal (right) regions; $D$, primary guard hair in shield region.

Figures E to I: scale patterns of hairs of Bettongia gaimardi. E, under hair in proximal region; F, under hair in mid-shaft region; $G$, under hair in distal region; $H$, primary guard hair in proximal region; $I$, primary guard hair in distal region. 


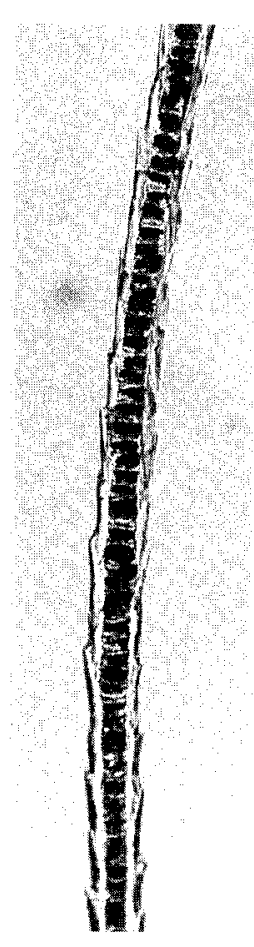

A

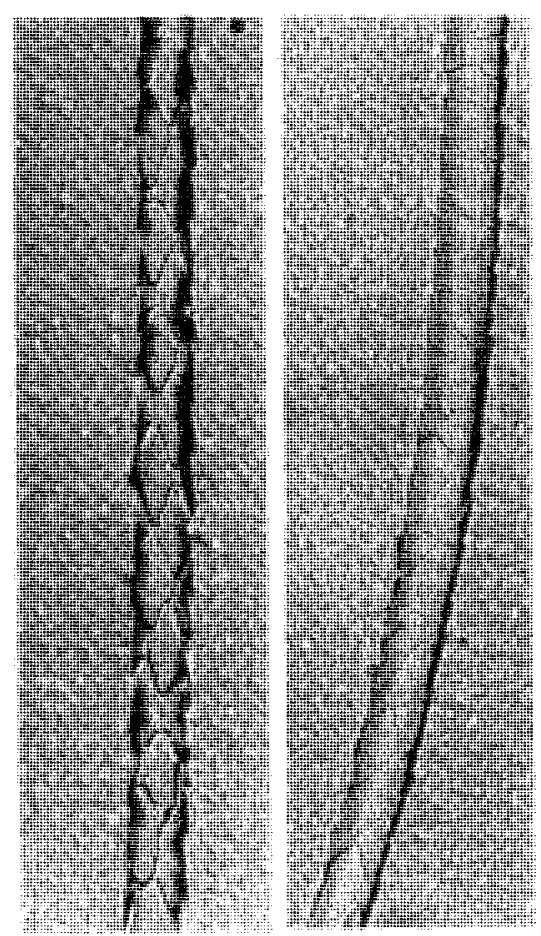

E

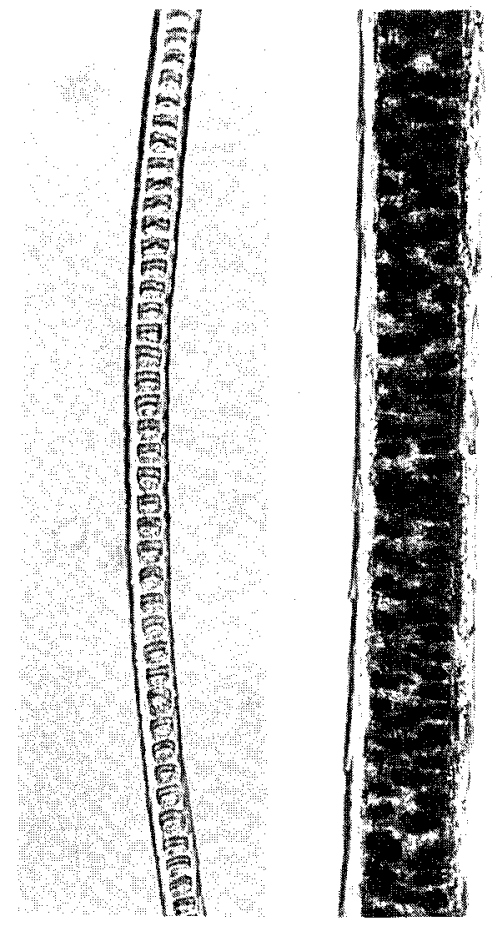

B

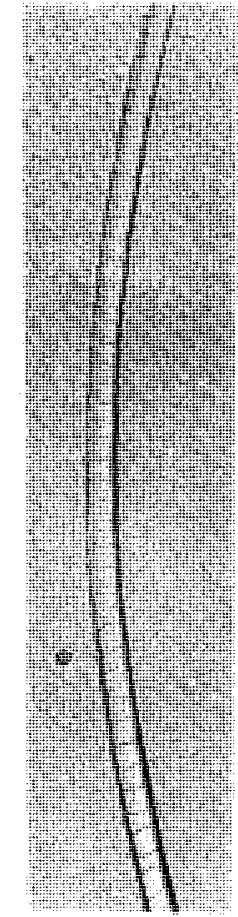

G

Identification of the hair of Tasmanian mammals.

81

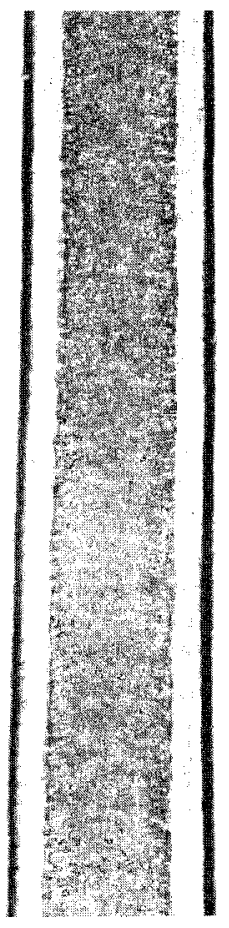

C

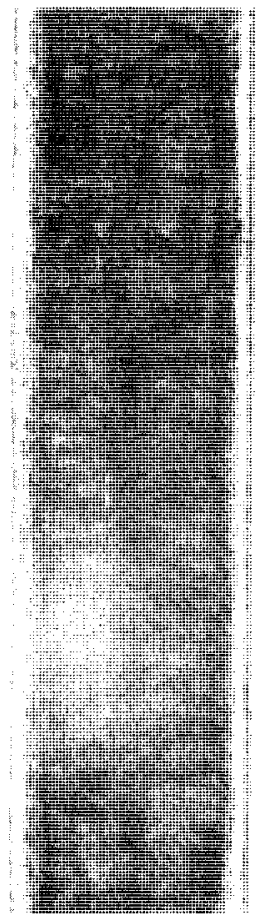

D

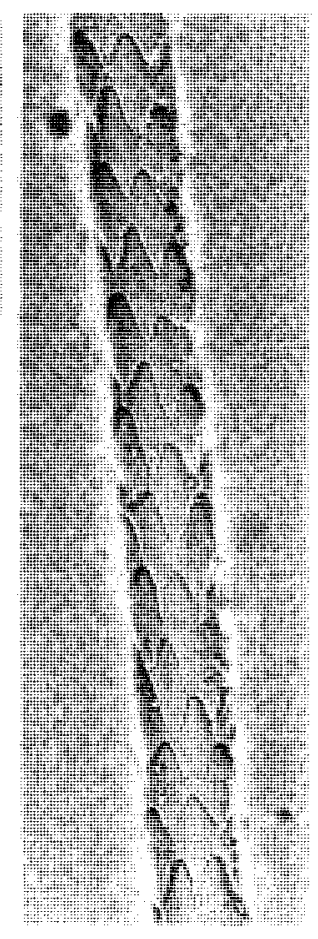

H

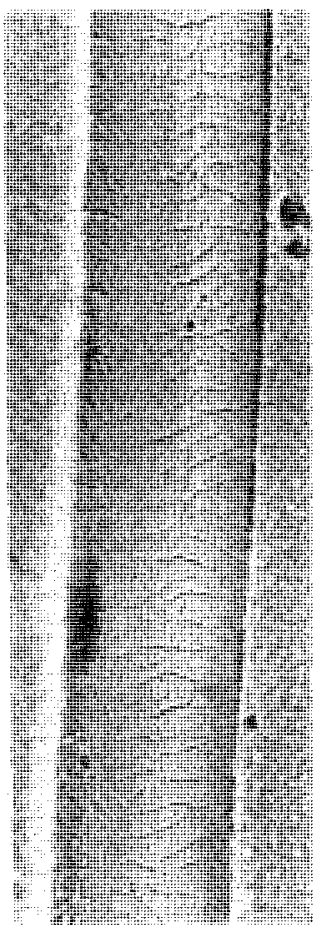

I

PLATE 10 
Tasmania. Some closely related species are difficult to distinguish from one another. These are: Antechinus swainsonii and A. minimus; Cercartetus nanus and $C$. lepidus, although the hair of $C$. nanus is probably slightly longer and wider than that of $C$. lepidus; and Pseudomys higginsi and Mastacomys fuscus.

In Victoria analysis of the hair in predator scats has proved to be a useful means of assessing the distribution and abundance of Mastacomys fuscus (Brunner \& Bertuch 1976). It was found in this study that Pseudomys higginsi, an endemic Tasmanian species, has hair which is difficult to separate from $M$. fuscus. This unfortunately limits the use of this technique as an aid in determining the status of this species in Tasmania. On the other hand the hair of Thylacinus cynocephalus was found to be distinguishable from other species and thus could be used in a search for this species.

Bats and seals were not included in this study as it was thought that these animals would only very rarely be present in predator scats. Dead seals may be occassionally scavenged by predators in coastal aras. Bats may be preyed upon by birds (Young 1980), and Maddock (1983) claims that Nyctophilus geoffroyi is frequently taken by domestic cats. The hair of bats can be easily identified by their characteristic scale patterns (see Brunner \& Coman 1974, pages 44-53).

\section{ACKNOWLEDGEMENTS}

I would like to thank Phil Andrews and Catherine Medlock (Tasmanian Museum), Bob Green(Queen Victoria Museum), Dave Rounsevell and Greg Hocking (Tasmanian National Parks and Wildlife Service) and Ron Mawbey, Wayne Kelly, Nick Savva and Randy Rose (University of Tasmania) for the provision of hair samples. Hans Brunner provided helpful comments on a draft of the paper.

\section{REFERENCES}

BRUNNER, H., AMOR, R.L. \& STEVENS, P.L., 1976: The use of predator scat analysis in a mammal survey at Dartmouth in north-eastern Victoria. Aust. Wildl. Res. 3: 85-90.

BRUNNER, H. \& BERTUCH, I.D., 1976: The Broadtoothed rat still in Sherbrooke Forest. A successful search for Mastacomys fuscus Thomas. Vict.Nat. 93: 55-56.

BRUNNER, H. \& COMAN, B.J., 1974: THE IDENTIFICATION OF MA MMALIAN HAIR. Inkata Press, Melbourne.

BRUNNER, H., LLOYD, J.W. \& COMAN, B.J., 1975: Fox scat analysis in a forest park in southeastern Australia. Aust. Wildl. Res. 2: 147-154.

JONES, E. \& COMAN, B.J., 1981: Ecology of the feral cat, Felis catus (L.), in south-eastern Australia. I. Diet. Aust.Wildl.Res. 8: 537-547.

LYNE, A.G. \& McMAHON, T.S., 1951: Observations on the surface structure of the hairs of Tasmanian monotremes and marsupials. Pap.Proc.R.Soc. Tasm. 1950: 71-84

MADDOCK. T.H., 1983: Lesser long-eared bat, Nyctophilus geoffroyi. In STRAHAN, R. (Ed.): COMPLETE BOOK OF AUSTRALIAN $M A M M A L S$. Angus and Robertson, Sydney, 331.

SUCKLING, G.C., 1978: A hair sampling tube for the detection of small mammals in trees. Aust. Wildl. Res. 5: 249-252.

VALENTE, A.\& WOOLLEY, P.A., 1982: Hair structure of some Western Australian mammals. J.R.Soc. W.A. 64: 101-132.

YOUNG, R.A., 1980: Observations on the vulnerability of two species of wattled bats (Chalinolobus) to diurnal avian predat ors. Vict. Nat. 97: 258-262.

(accepted May 10, 1985) 